\section{The vividness of connotative adjectives and their paired-associate learning}

\author{
LIILABETH P. KIRCHNER, The \\ Pennsylvania State University, University \\ Park, Pa. 16802
}

Greater PA learning of connotative adjectives is associated with the vividness of the PA stimulus. Poorer PA learning is associated with the vividness of the $P A$ response. The impact of vividness on $P A$ learning is hypothesized to result from an associated alerting effect. Vividness. imagery, and meaningfulness are compared.

Although the conceptual history of vividness (V) extends to the writings of Thomas Brown (1820) who proposed $V$ as a secondary law of learning. and although early investigators, such as Calkins (1894), manipulated $\mathrm{V}$ by means extornal to the stimulus words themselves (e.g., printing in a contrasting color: gestural or inflectional emphasis), the investigation of $\mathrm{V}$ conceived of as a property intrinsic to the stimulus has received scant attention. Regarding nouns. $V$ as an inherent stimulus quality has been shown to influence positively their free recall (Tulving, McNulty, \& Ozier, 1965) and recognition (Miller \& Dost. 1964). The present author (Kirchner, 1969) found the $V$ of connotative adjectives to influence the recall of connected discourse and postulated that $\mathrm{V}$ may involve an alerting or energizing function inasmuch as $\mathrm{V}$ was related to recall of modified nouns and to sheer productivity, but not to the recall of the specific adjectives themselves.

The present study was designed to explore the role of $\mathrm{V}$ in the paired-associate (PA) learning of connotative adjectives utilizing lists in which stimulus and response $V$ were systematically varied. Also investigated among the items utilized in this study were the relationships between $\mathrm{V}$ and imagery (l) (cf. Paivio, 1965) and between $V$ and meaningfulness $(\mathrm{m})$ (Noble, 1952). It was predicted that $\mathrm{V}$, involving an arousing or alerting function as hypothesized in the earlier study, would facilitate PA learning on both the stimulus and the response side. Further, to the extent that $\mathrm{V}$ and I represent a common variable, one would expect the effects of $\mathrm{V}$ on PA learning to be similar to that of $\mathrm{I}$ : a greater impact as a stimulus variable than as a response variable. Likewise, the four stimulus-response combinations of high $\mathrm{V}$ and low $V$ (here referred to as dull, D) would, according to this reasoning, be learned in the sequence of $V V, V D, D V$, and DD, in order of increasing difficulty. Predictions based on any hypothesized close relationship between $V$ and $m$ are less straightforward; different PA studies have shown a greater effect for both response $m$ and stimulus $m$. However, Epstein (1963) has postulated that the effects of stimulus and response $m$ should be equal when the need for response learning is minimal, as would be the case in this study, which utilized words presumably completely familiar to Ss.

\section{MATERIALS}

The items of PA learning were $16 \mathrm{~V}$ adjectives and $16 \mathrm{D}$ adjectives. They were selected for their divergence in $\mathrm{V}$ and their similarity in frequency of occurrence from a pool of 68 adjectives for which ratings on a 7-point scale of the dimension "vivid-colorless" had been obtained from 30 male and female college Ss, following the procedure of Jenkins, Russell, \& Suci (1958). (Vividness ratings of 33 adjectives, including 13 adjectives utilized in the present study, were found to have an intergroup reliability of .97). The V adjectives had a mean rating of $1.62 \pm .26$; the $D$ adjectives had a mean rating of $5.03 \pm .61$. Thorndike \& Lorge (1944) frequencies for all adjectives were between 1 and 38 occurrences per million, the mean frequency of the $V$ adjectives being $17.5 \pm 11.5$ and that of the $D$ adjectives being $17.5 \pm 10.6$. The $V$ adjectives are: animated, brutal, cheerful, colorful, exalted, gorgeous, luxurious, marvelous, radiant, ripe, shrill, sparkling, starving, tantalizing, wicked, and wondrous. The D adjectives are: bleak, blunt, confused, crude, dim, dreary, homely, indifferent, inferior, lenient, lonely, mild, obscure, shallow, somber, and stagnant.

To control for possible biases favoring the learning of specific pairs, four PA lists consisting of 16 pairs were constructed, utilizing a method closely paralleling that of Paivio (1965). Each list contained four pairs of each of the following combinations: VV, VD, DV, and DD. The pairing for the first list was random except for the restrictions that meaningful associations and alliterative pairs were not permitted. The second list was devised by recombining adjectives from $\mathrm{VV}$ and $\mathrm{DD}$ pairs of the first list as VD and DV pairs in the second and by recombining $\mathrm{VD}$ and DV pairs of the first list as VV and DD pairs of the second. The third and fourth lists were constructed by reversing the stimulus and response positions of the pairs in the first two lists.

PROCEDURE

Paired-Associate Learning

Ninety-seven Ss were divided into four roughly equal groups. Each group learned, via auditory presentation, one of the PA lists described above. There were four learning trials, in which both stimulus and response members were presented, in alternation with four recall trials, in which the stimulus members alone were presented.

Instructions to Ss included an example utilizing oral presentation of four noun PAs followed by oral presentation of the stimulus terms, together with a request that Ss call out the appropriate response terms. During recall trials of the study, Ss wrote the response terms on response sheets, one for each trial, containing the numbers 1.16 in a column. Pairs were read aloud in a monotone on each learning trial, approximately $2 \mathrm{sec}$ elapsing between pairs. On each recall trial, the stimulus words alone were read at 8-sec intervals, each stimulus word being preceded by its ordinal number to facilitate the accurate recording of responses. Each learning trial and each recall trial involved a different random serial order of items. Immediately after each recall trial, the completed response sheets for that trial were collected and the next learning trial promptly began. Imagery

The 32 adjectives utilized in this study were submitted to 40 independent Ss for rating on a 7-point scale of $I$. The procedure for obtaining I ratings was patterned after that of Paivio (1965), although the present procedure utilized a 7-point, rather than a 5-point, scale. Three practice words (a noun, an adjective, and a verb) were utilized in the instructions. Mimeographed booklets were prepared for the I ratings utilizing four pages (of eight adjectives each) arranged in 12 possible combinations of four pages.

Meaningfulness

Forty-three additional Ss provided data on $m$ of the adjectives of this study. Instructions to Ss were similar to those originally described by Noble (1952). The Ss provided written 1 -min continued associations in booklets in which the 32 words were presented one to a page, 20 times per page in two columns. Sixteen different random orders of the 32 words were utilized.

The Ss were Pennsylvania State University students in an introductory psychology course who were rewarded by a small increment in course grade. Ninety-seven female Ss participated in the PA experiment: 20 male and 20 female Ss 
provided data on $I$, and 22 male and 21 female Ss provided data on $m$. No $\mathrm{S}$ participated in more than one phase of the study.

\section{RESULTS}

Vividness and

Paired-Associate Learning

Data from the four groups of Ss, being highly similar when plotted graphically, were pooled for analysis. Graphic plotting of the mean number of correct response recalls on each trial revealed no interaction of trials and different stimulus and response combinations, hence the recall scores utilized in the statistical analyses are the total number of correct responses on the four trials. An analysis of variance with repeated measures (Winer, 1962) was performed on these recall scores to evaluate the relative impact of stimulus and response $\mathrm{V}$. This analysis yielded an $\mathrm{F}$ of 33.83 for stimulus $\mathrm{V}(\mathrm{df}=1 / 96, \mathrm{p}<.005)$, an $F$ of 5.40 for response $V(d f=1 / 96$, $\mathrm{p}<.05)$ and a nonsignificant interaction $(F=1.16)$. The means and standard deviations of recall scores for the four combinations of stimulus and response $\mathrm{V}$ are presented in Table 1 . The results regarding stimulus $\mathrm{V}$ support the prediction of greater recall related to $\mathrm{V}$, but note that the results for response $V$ are contrary to predictions; superior recall accrues to the dull PA responses. Differences between pairs of means, when tested by $t$ tests for correlated means, are all significant at the .05 or .01 probability level, with the exception of that of VV and VD comparison. In order of increasing difficulty, then, the four combinations were learned in the sequence $\mathrm{VV}=\mathrm{VD}>\mathrm{DD}>\mathrm{DV}$. Such findings are clearly not in accord with predictions based on assumptions regarding similar effects for $V$ and $I$.

In addition to the analysis of correct recall scores, attention was paid to intrusion errors occurring to the four different types of pairs on the first recall trial (the only trial on which sufficient errors occurred to warrant analysis). Table 2 presents both the number of all intrusions (within-list plus extra-list) and the number of within-list intrusions occurring on the first recall trial for each of the four combinations of stimulus and response V. For total intrusions,

Table 1

Mean Correct Responses Over Four Trials of PA Pairs Varying in Stimulus and Response Vividness

\begin{tabular}{lcc}
\multicolumn{2}{c}{ and Response Vividness } \\
\hline & \multicolumn{2}{c}{ Response } \\
\cline { 2 - 3 } Stimulus & Vivid & Dull \\
\hline Vivid & $8.65 \pm 3.37$ & $8.88 \pm 3.39$ \\
Dull & $6.98 \pm 3.97$ & $7.69 \pm 3.98$ \\
\hline
\end{tabular}

frequencies in the four categories are different from those expected by chance $\left(\chi^{2}\right.$ one-sample test; $\chi^{2}=9.81, \mathrm{df}=3$, $\mathrm{p}<.05$, two-tailed); total intrusions are significantly related to response $\mathrm{V}$ when analyzed by the binomial test ( VV + DV $>$ $\mathrm{VD}+\mathrm{DD} ; \mathrm{Z}=2.03, \mathrm{p}<.04$, two-tailed) but are not related to stimulus $\mathrm{V}$ $(\mathrm{VV}+\mathrm{VD}$ vs $\mathrm{DV}+\mathrm{DD} ; \mathrm{Z}=.38, \mathrm{p}>.70)$ When within-list intrusions are isolated from total intrusions and subjected to similar analyses, category frequencies are again distributed contrary to chance expectancy $\left(\chi^{2}=8.90, \mathrm{df}=3, \mathrm{p}<.05\right.$, two-tailed). Within-list intrusions appear related to stimulus $\mathrm{V}(\mathrm{VV}+\mathrm{VD})$ $D V+D D ; \quad Z=1.70, p<.08$, two-tailed binomial test) but not to response $V$ $(\mathrm{VV}+\mathrm{DV}$ vs VD + DD; $\mathrm{Z}=1.10, \mathrm{p}>.26)$ Within-list intrusions were then classified according to whether the individual intrusions were $V$ or $D$ items. Such intrusions were analyzed for their "congruence," in terms of V, with both the stimulus $V$ and response $V$ of the $P A$ pair to which they occurred. Stated another way, intrusions occurring to vivid stimulus PAs were classified as congruent if they "intruded" from other vivid stimuli or from vivid responses and as noncongruent if they "intruded" from dull stimuli or from dull responses; analogous classifications were made for intrusions occurring in response to dull.PA stimuli and to PAs of vivid and of dull responses in the original PA list. Within-list intrusions appear to be congruent with the $\mathrm{V}$ of the stimulus (161 errors congruent with the stimulus vs 109 noncongruent errors; $Z=3.16, p<.002$, two-tailed binomial test) but not with the $V$ of the originally correct response (144 congruent errors vs 126 noncongruent errors; $Z=1.09$, $\mathrm{p}>.26)$.

To summarize these results, in PA learning vivid (vs dull) stimuli lead to greater learning, no difference in total intrusions, more within-list intrusions, and congruence of within-list intrusions. On the response side of $\mathrm{PA}$ learning, dull responses are superior on recall and more total intrusions occur when the required response is vivid; the number of within-list intrusions, however, is not related to the $\mathrm{V}$ of the required response, nor are the

Table 2

Total and Within-List Intrusions Occurring on the First Recall Trial

Type of Intrusion

\begin{tabular}{lcc}
$\begin{array}{c}\text { Type } \\
\text { of PA }\end{array}$ & Toial & $\begin{array}{c}\text { Within- } \\
\text { List }\end{array}$ \\
\hline VV & 105 & 88 \\
VD & 65 & 61 \\
DV & 80 & 56 \\
DD & 83 & 65 \\
\hline
\end{tabular}

intrusions more congruent than noncongruent with the $\mathrm{V}$ of the required responses.

\section{Vividness and \\ I and $m$ Ratings}

Ratings on $m$ for each of the 32 adjectives were based upon the average of the total number of different associations given by each $S$. The mean of these average $m$ scores for the $\mathrm{V}$ adjectives is $9.18 \pm .91$. and that for the $\mathrm{D}$ adjectives is $8.40 \pm .63$; the difference, while not great, is statistically significant $(t=2.73, p<.05)$. Mean I ratings, based on average I for each word, are $5.31 \pm .72$ for the $V$ adjectives and $4.57 \pm .87$ for the $D$ adjectives, again a statistically significant difference $(t=2.55$, $\mathrm{p}<.05$ ) which appears small in absolute magnitude. Note also that mean I ratings for both the $\mathrm{V}$ and $\mathrm{D}$ adjectives are above the midpoint of the 7-point scale of ease or speed of image arousal.

Correlations were computed among V, I, and $m$. Obtained were a point-biserial correlation of .42 between $V$ and $I$, a point-biserial correlation of .52 between $V$ and $m$. and a product-moment correlation of .58 between I and $m$. The range of mean $I$ ratings for all items was 3.5-6.2 and that of mean $m$ ratings was 7.4-10.4; some restrictions of range must be borne in mind in interpreting the correlations involving these variables.

The contributions of $I$ and $m$ to recall scores were investigated by computing correlations between mean scores on these attributes and mean recall scores for each of the 32 adjectives in both their stimulus and their response positions. Recall scores correlated .29 and .08 with stimulus I and $m$, respectively, and correlated .15 and .15 with response $\mathrm{I}$ and $m$. None of these correlations is statistically significant.

\section{DISCUSSION}

To be accounted for are results not in accord with predictions based upon hypothesized relationships of $\mathrm{V}$ and $\mathrm{I}$ or with $m$. First of all, neither these relationships nor the relationships of I and $m$ to recall scores possess magnitudes allowing reliance upon them in accounting for the results of this study. More importantly, the major finding, that $\mathrm{V}$ has significant but opposite effects as a stimulus variable and as a response variable in the recall of paired associates, is bereft of theoretical aid from work on either $I$ or $\mathrm{m}$; it is the reversal of effects of $\mathrm{V}$ for the stimulus and response components that eliminates the explanatory usefulness of such conceptualizations.

The uniqueness of this reversal of effect and its unpredicted occurrence leads to explanatory attempts that can be offered as only speculative and as clearly requiring further exploration. It is suggested that the 
alerting or energizing function of $\mathrm{V}$ hypothesized earlier may be able to encompass the results of this study. By such reasoning. a vivid stimulus leads to greater alerting. attending. etc.. on the part of $\mathrm{S}$. The $\mathrm{S}$ is hence more attentive to and likely to learn the associated response and other words within the list. The $V$ of the $\mathrm{PA}$ response again involves greater alerting. but this alerting, coming as it does at the end of a PA pair and prior to a lengthier time interval than that between the two PA components, leads to a "spread" of attending. Hence, there would be a facilitation and the learning of other elements within S's immediate situation (e.g. free associates of the PA response item and extraneous material in the total stimulus environment of $S$ ) that would embarrass the likelihood of recall of the correct PA response and enhance the likelihood of intrusions (although not of within-list intrusions). Further work, particularly with unmixed list designs, should clarify some of these effects and perhaps shed further light on the findings regarding congruence in $\mathrm{V}$ of within-list intrusions. Also, inasmuch as the adjectives utilized here were connotative adjectives, the exploration of $\mathrm{V}$ should be extended to other form classes and to adjectives of other types (e.g., descriptive and more "concrete" adjectives, such as those specifying size, color, and sensory qualities) in an attempt to understand if the present $V$ effects are specific to adjectives and/or to the connotative nature of the present materials. RIIERINCES

BROWN. T. lectures on the philosophy of the human mind. Hallowell, Iingland: Masters. Smith, 1854

CALKINS, M. W. Relative significance of frequency, vividness, recency, and earliness as conditions of association. Psychological Review, 1894, 1, 476-483.

EPSTEIN, W. The effect of stimulus and response meaningfulness when response availability is equated. Journal of Verbal Learning \& Verbal Behavior, 1963, 2, 242-249.

HAAGEN, C. H. Synonymity, vividness, familiarity and association value ratings of 400 pairs of common adjectives. Joumal of Psychology, 1949, 27, 453-463

JFNKINS, J. J.. RUSSELL, W. A., \& SUCI, G. J. An atlas of semantic profiles for 360 words. American Journal of Psychology, 1958, 71, 688-699.

KIRCHNER, F. P. Vividness of adjectives and the recall of meaningful verbal material. Psychonomic Science. 1969, 15, 71-72.

MILLER, M. F.., \& DOST, J. A. Stimulus vividness and anxiety level in intentional-incidental learning. Psychological Reports, 1964, 14, 819-825.

NOBLE, C. F. An analysis of meaning Psychological Review, 1952, 59, 421-430.

PAIVIO, A. Abstractness, imagery, and meaningfulness in paired associate learning. Journal of Verbal Learning \& Verbal Behavior, $1965,4,32-38$.

THORNDIKE, E. L., \& LORGE, I. The teacher's word book of 30,000 words. New York: Bureau of Publications, Teachers College, Columbia University, 1944.

TULVING, E., McNULTY, J. A., \& OZIER, M. $V$ ividness of words and learning to learn in free recall learning. Canadian Journal of Psychology, 1965, 19. 242-252.

WINER, B. J. Statistical principles in experimental design. New York: McGraw-Hill, 1962. studies have not always kept to this gradual-incremental sequence. Sometimes, the individual delays have been randomized (e.g., House \& Zeaman, 1961) and, in other cases, the delays have been presented in a linear fashion but hardly on an incremental basis, since large durational changes occurred between adjacent intervals (Allen, 1931).

Fletcher (1965) has proposed that during the delay interval, the organism engages in overt and/or covert forms of orienting behavior that are part of a response chain initiated by an observing response at the time of baiting and ended by an instrumental response at the moment of choice. Accordingly, procedures that destroy the integrity of the chain will lower delayed-response performance. A sudden change in the size of the delay interval is one such procedure for disrupting the length of efficient orienting behavior and thus is the variable of primary concern herein.

\section{METHOD}

Forty infants, 16 to 24 months old, with a median age of 19 months, were Ss. They came from two orphanages and one shelter home and were tested in unused rooms therein.

A modified WGTA was used. A description of the preliminary adaptation and baiting procedures is given in detail elsewhere (Weisberg \& Simmons, 1963). The interior of the WGTA at S's end contained a locked stimulus tray on which were two foodwells, spaced 8 in. apart. E, seated behind the apparatus, string-manipulated a frontally located opaque and transparent screen and observed S's choice response through a one-way-vision mirror that was attached to the rear of the apparatus. S sat strapped to a highchair sans feeding tray. The WGTA rested on a table adjusted in height so that S's eye level was perpendicular to the stimulus display. When the transparent screen was raised midway, it started an electric timer that stopped as soon as one of the plaques covering a foodwell was half exposed.

At the beginning of every trial, $E$ raised the opaque screen and rapped on the unraised transparent screen to gain S's attention. With both foodwells exposed, E displayed and placed a snack in one of the foodwells, then took $2 \mathrm{sec}$ to point to the baited well before both foodwells were covered with two identical gray wooden plaques. For a 0 -sec delay, the transparent screen was immediately lifted and $S$ was allowed to uncover one of the plaques. This procedure was repeated with all delays longer than $0 \mathrm{sec}$, except that the transparent screen remained down throughout the delay interval; hence, S's 